\title{
Surgical correction for adult spinal deformity (1) updates
updat increases acetabular lateral coverage of femoral heads
}

Qiang Luo ${ }^{1,2+}$, Yong-Chan Kim ${ }^{1 \dagger}$, Ki-Tack Kim ${ }^{1}$, Kee-Yong Ha ${ }^{1}$, Young-Soo Chun ${ }^{1}$, Joonghyun Ahn ${ }^{{ }^{*}}$ (D), Sung-Min $\mathrm{Kim}^{1}$ and Kyeonguk Min ${ }^{1}$

\begin{abstract}
Background: Studies explaining the relationship between hip and spine reported that spinal corrective surgery affected acetabular orientation and changes in pelvic tilt were capable of influencing radiographic measures of acetabular coverage. This study aimed to assess the change in coronal parameters for acetabular coverage as a result of adult spinal deformity (ASD) correction and to analyze the relationship between the postoperative changes in sagittal spinopelvic parameters and coronal acetabular coverage parameters.
\end{abstract}

Methods: Fifty-two consecutive patients who had undergone multilevel spinal surgical correction were enrolled and evaluated. Coronal acetabular coverage parameters included Tönnis angle (TA), lateral center edge angle (LCEA), and the angle of Sharp (SA). All radiographic parameters were evaluated at the preoperative and the postoperative 1 year. Paired t test was used to determine whether there were significant changes between the time points. Bivariate correlation and linear regression analysis were used to assess the relationship between the postoperative changes of spinal alignment and acetabular orientation.

Results: The surgical correction resulted in significant decrease of TA, increase of LCEA and SA, respectively $(p<0.001)$. The changes in pelvic tilt (PT) demonstrated weak correlation on TA $(\beta=0.117, p<0.001$ for right; $\beta=0.111$, $p<0.001$ for left).

Conclusions: Although the surgical correction of ASD significantly changed PT resulting in increased acetabular lateral coverage parameters, the correlation between the changes of PT following sagittal correction of ASD and acetabular coverage parameters was low.

Trial registration: This study was retrospectively registered with approval by the institutional review board (IRB) of our institution (approval number: KHNMC-2020-10-010).

Keywords: Adult spinal deformity, Tönnis angle, Lateral center edge angle, Angle of sharp, Pelvic tilt

*Correspondence: ajhssnim@gmail.com

†Yong-Chan Kim and Qiang Luo contributed equally to this work. 1 Department of Orthopaedic Surgery, Spine Center, Kyung Hee University Hospital at Gangdong, 892, Dongnam-ro, Gandong-gu, Seoul 05278, South Korea

Full list of author information is available at the end of the article

\section{Background}

Adult spinal deformity (ASD), regardless of its subtype, is usually characterized by a tendency of bending upper body forward or kyphotic deformity [1]. Fortunately, to some extent, the spinal kyphotic deformity in standing human body can be compensated via hip extension and its resultant change in pelvis which is called pelvic tilt (PT). On the contrary, if the spinal sagittal malalignment original author(s) and the source, provide a link to the Creative Commons licence, and indicate if changes were made. The images or other third party material in this article are included in the article's Creative Commons licence, unless indicated otherwise in a credit line to the material. If material is not included in the article's Creative Commons licence and your intended use is not permitted by statutory regulation or exceeds the permitted use, you will need to obtain permission directly from the copyright holder. To view a copy of this licence, visit http://creativecommons.org/licenses/by/4.0/. The Creative Commons Public Domain Dedication waiver (http://creativeco mmons.org/publicdomain/zero/1.0/) applies to the data made available in this article, unless otherwise stated in a credit line to the data. 
is recovered by a corrective surgery, $\mathrm{PT}$ as a compensatory mechanism is expected to be changed in a return to its normal position. Thus, the orientation of acetabulum in the pelvis can be also expected to be changed by a corrective surgery on spinal column with sagittal malalignment. In the recent decade, the studies explaining the relationship between hip and spine has been reported that spinal corrective surgery affected acetabular orientation including change of anteversion [2-4]. In addition, Watanabe et al. demonstrated that PT increased in patients with decreased lumbar lordosis (LL) and acetabular coverage of anterior femoral head decreased compared to the controls [5]. Therefore, kyphotic spinal deformity causing excessive PT can substantially contribute to the instability or the risk of dislocation following total hip arthroplasty (THA). In THA for patients with ASD, the planned anteversion and inclination should be less than the native anatomy to prevent risk of anterior instability. Previous studies reported changes in PT could significantly influence radiographic measures of acetabular coverage in cadaveric models [6-8].

Although the correlations were identified in previous cadaveric studies or clinical studies, there had been a paucity of reports clarifying how sagittal deformity correction for patients with ASD significantly increase the acetabular coverage by decrease in PT, increase in LL and consequently alter 3 radiographic measures of acetabular anatomy such as lateral center edge angle (LCEA) [9], Tönnis angle (TA) [10], and the angle of Sharp (SA) [9] and quantifying the relative radiographic changes between the parameters. Therefore, this study aimed to assess and quantify the change in coronal parameters for acetabular coverage as a result of ASD correction and analyze the relationship of postoperative changes of sagittal spinopelvic parameters and the coronal parameters for acetabular coverage. We hypothesized that an alteration in PT following ASD correction would produce significant and predictable differences in the measure of the LCEA, TA and SA. A further understanding of these radiographic relationship may improve surgical plan for patients with concomitant pathologies on both hip and spine.

\section{Methods}

\section{Study design \& patient population}

After obtaining approval (approval number: KHNMC2020-10-010) by the appropriate ethics committee (institutional review board of our institution), a retrospective review of radiographic and clinical data was performed in accordance with the ethical standards laid down in the 1964 Declaration of Helsinki. This study was performed with adult spinal deformity (ASD) patients who had undergone spinal surgical correction between March
2011 and May 2018 at a single institution. The inclusion criteria were as follows: (1) preoperative diagnosis of degenerative lumbar kyphosis or kyphoscoliosis; (2) completion of a long-segment spinal fusion surgery from the level of thoracolumbar junction (T9 to L1) to the sacrum with bilateral S1 pedicle screws and iliac screws for lumbosacral fixation; and (3) postoperative follow-up period of more than 1 year. The exclusion criteria were as follows: (1) sagittal balance as sagittal vertical axis (SVA) less than $5 \mathrm{~cm}$ and PT less than $20^{\circ}$ on lateral radiograph in standing position; (2) inadequate visibility for measuring radiographic parameters in whole spine standing anteroposterior (AP) and lateral radiographs at regular pre- and postoperative visits; (3) radiographic evidence of osteoarthritis as defined by less than $2 \mathrm{~mm}$ of remaining joint space or hip dysplasia; (4) preoperative coronal balance (CB) of $>3 \mathrm{~cm}$ or leg length discrepancy (LLD) of $>1 \mathrm{~cm}$; (5) peripheral vascular disease; (6) any syndromic, neuromuscular disease; (7) evidence of previous hip surgery; (8) evidence of previous spine fusion surgery; (9) early (within 1 year) postoperative complications requiring revisional operation for index surgery; (10) if they lacked either baseline or postoperative imaging at regular follow-up; and (11) if there was an obstruction of the normal acetabular ellipse.

\section{Radiographic assessment}

Standing 36-in.-long cassette AP and lateral radiographs of the whole spine were measured preoperatively and at 1-year postoperative follow-up, respectively. On the radiographs, sagittal vertical axis (SVA): the distance between the $\mathrm{C} 7$ plumb line and the posterior-superior corner of S1; cervical lordosis (CL) [11]: the angle between the inferior $\mathrm{C} 2$ endplate and the $\mathrm{C} 7$ endplate; thoracic kyphosis (TK) [11]: the angle between the upper endplate of the T5 vertebra and the lower endplate of the T12 vertebra; thoracolumbar kyphosis (TLK) [11, 12]: the angle between the upper endplate of the T10 vertebra and the lower endplate of the L2 vertebra; lumbar lordosis (LL) [11]: the angle between the superior L1 endplate and the S1 endplate; PT [11]: the angle between the vertical line and the line joining the middle of the sacral plate and the hip axis; and pelvic incidence (PI) [11-13]: the angle between the perpendicular of the sacral plate and the line joining the middle of the sacral plate and the hip axis; were measured. The angle was defined as positive if the curve is kyphotic and as negative if the curve is lordotic. We also performed standard coronal measurements of spinopelvic parameters using standing anteroposterior radiographs: coronal balance (CB) [12]: lateral distance of the $\mathrm{C} 7$ plumb-line to the center sacral vertical line; and pelvic obliquity (PO) [12]. 
.Coronal acetabular coverage parameters included TA, LCEA, and SA (Fig. 1). The TA was measured between a horizontal reference and a line formed parallel to the most medial and lateral extents of the sclerotic weight bearing portion of the acetabulum [6]. The LCEA was calculated by superimposing a circle over the acetabulum and measuring the angle between a vertical reference and the lateral edge of the sourcil with the apex at the center of the superimposed circle [6]. The SA's apex was centered at the inferior radiographic teardrop and measured between a vertical reference and the lateral acetabular rim [6]. These coronal acetabular parameters were measured on standing, posterioranterior, 36-in. long radiograph. Of note, the protocol for image acquisition called for a weight-bearing, freestanding, comfortable position with arms flexed at 45 degrees to avoid superimposition with the spine [14].

\section{Inter- and intraobserver reliability}

Intraclass Correlation Coefficients for acetabular lateral coverage parameters were calculated within and between the observers by selection of randomly selected 20 patients among included patients. All measures were independently acquired and recorded by 2 observers (JA, SMK). The measures were taken at 2 separate time points, a minimum of 2 weeks apart. To reduce random error, then, the measured values were averaged for statistical analysis with spinopelvic parameters.

\section{Statistical analysis}

All statistical analysis were performed with SPSS software (version 21.0, Armonk, NY, USA). Completecase analysis was used and data were summarized by mean \pm standard deviation (SD) or range for numeric variables. Distribution normality was assessed using the Kolmogorov-Smirnova test. Paired t test was used to compare the measured values between pre- and

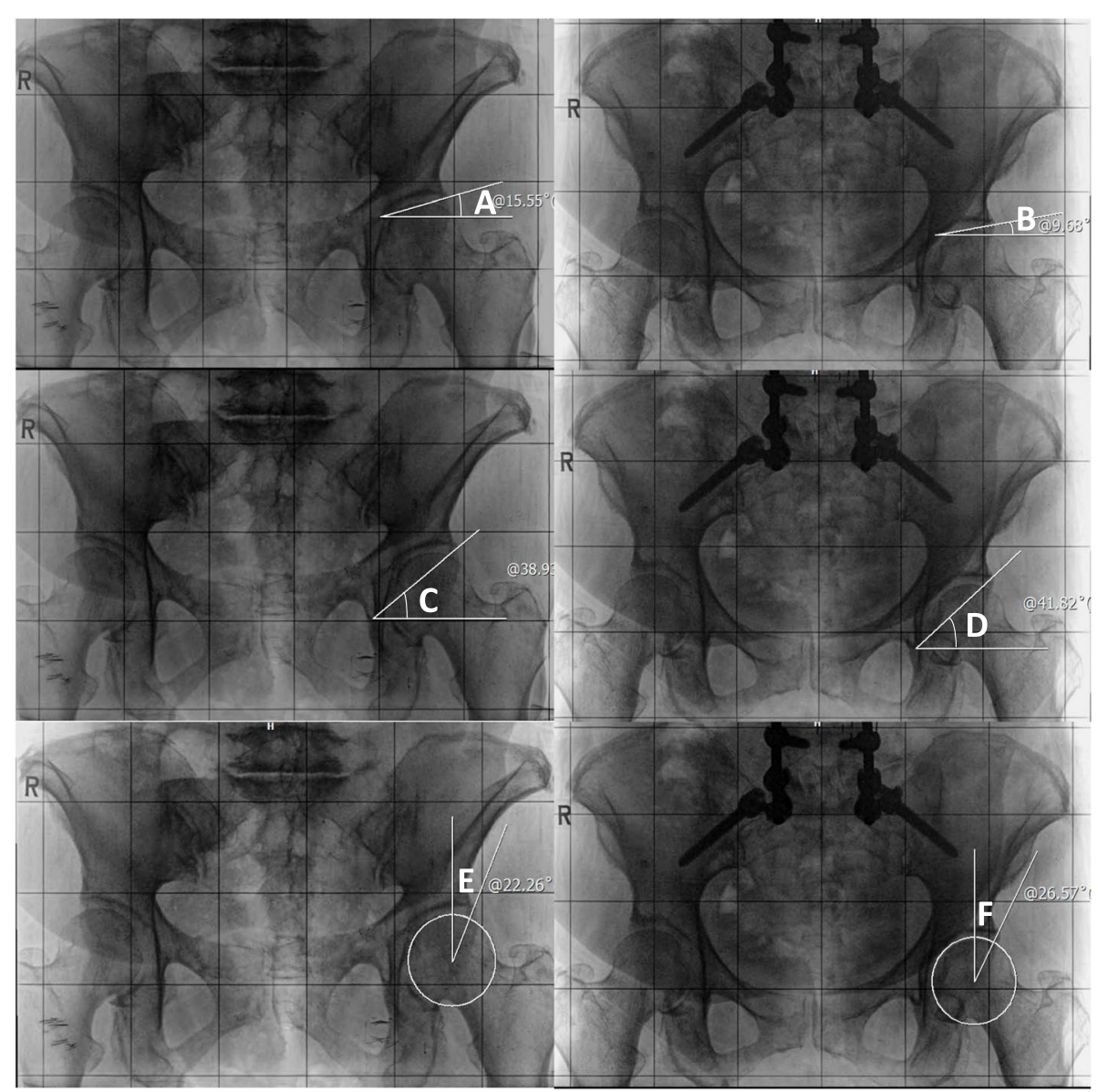

Fig. 1 Posterior-anterior pelvic radiographs of a 72-year-old female patient showing the changes in acetabular coverage after surgical correction for ASD. Note that TA decreased after surgery. On the other hand, SA and LCEA increased. A Preoperative TA left. B Postoperative TA left. C Preoperative SA left. D Postoperative SA left. E Preoperative LCEA left. F Postoperative LCEA left 
postoperative spinopelvic and acetabular coverage parameters. Jonkheere-Terpstra test was used to compare the coronal acetabular coverage parameters (TA, LCEA, and SA) among three groups (Group I: PI < 45, Group II: PI $45-60^{\circ}$, Group III: PI $>60^{\circ}$ ) for both sides of hip. The effect of change in spinopelvic parameters on the change of coronal acetabular coverage parameters was determined by bivariate correlation analysis and linear regression analysis. Statistical significance was set at $P<0.05$.

\section{Results}

\section{Demographics and clinical details}

Among the 144 consecutively treated ASD patients, a total of 52 patients (104 acetabulum) met the study inclusion criteria. There were 42 women $(86.1 \%)$ and 10 men (13.9\%). The age of patients was $69.5 \pm 3.8$ (range, 62-77) years and body mass index (BMI) was $23.2 \pm 5.6$ (range, $16.9-35.2) \mathrm{kg} / \mathrm{m}^{2}$. The demographic and clinical data were further summarized in Table 1.

\section{Repeatability and reproducibility of measurement}

Intra- and interobserver correlation coefficients for each measure of acetabular lateral coverage parameters ranged between 0.86 and 0.92 , and 0.87 and 0.96 for each observer and separate time point, respectively (Table 2 ).

\section{The changes of spinopelvic parameters after ASD correction}

Significant sagittal radiographic correction was achieved with surgery for SVA, CL, TLK, LL, PT, and PI-LL $(P<0.05)$. The spinopelvic alignment was significantly improved at 1 year postoperatively. SVA, PI-LL, and PT decreased significantly from baseline to the 1-year postoperative follow-up (SVA: [13.6 \pm 6.4 to $3.7 \pm 2.2, p<0.001]$, PI-LL: $[37.1 \pm 16.2$ to $9.6 \pm 5.5$, $p<0.001]$, PT: $[32.9 \pm 8.1$ to $20.4 \pm 5.7, p<0.001])$. LL,

Table 1 Demographic Characteristics of the Patients

\begin{tabular}{ll}
\hline Gender & 42 women; 10 men \\
\hline Age (years) & $69.5 \pm 3.8$ (range, 62-77) \\
BMI ( $\left.\mathrm{kg} / \mathrm{m}^{2}\right)$ & $23.2 \pm 5.6$ (range, 16.9-35.2) \\
Diagnosis & \\
$\quad$ Degenerative lumbar kyphosis & 34 cases \\
$\quad$ Degenerative lumbar kyphoscoliosis & 18 cases \\
Number of fusion levels & $8.0 \pm 0.6$ (range, 6-9) \\
T9 to Sacrum(9 levels) & 8 cases \\
T10 to Sacrum(8 levels) & 40 cases \\
T11 to Sacrum(7 levels) & 2 cases \\
T12 to Sacrum(6 levels) & 2 cases \\
\hline
\end{tabular}

BMI Body Mass Index.

The data in the table are presented as mean \pm standard deviation or range.
SS, and TK increased from baseline to the 1-year postoperative follow-up (LL: $[15.4 \pm 14.5$ to $-44.4 \pm 7.7$, $p<0.001]$, SS: $[22.0 \pm 9.0$ to $32.4 \pm 8.7, p<0.001]$, TK: $[13.1 \pm 11.7$ to $26.5 \pm 8.7, p<0.001])$. In addition, the absolute value of coronal radiographic measurements such as $\mathrm{CB}$ and $\mathrm{PO}$ decreased significantly after surgery (CB: $[10.3 \pm 8.6$ to $3.6 \pm 2.8, p<0.001]$, PO: $[1.0 \pm 0.9$ to $0.6 \pm 0.6, p=0.002])$. These changes of spinopelvic parameters after ASD correction are summarized in Table 3.

Table 2 Intra- and Interobserver agreement

\begin{tabular}{lll}
\hline Variable & Intra-observer ICC $\mathbf{( 9 5 \% ~ C I )}$ & $\begin{array}{l}\text { Inter-observer } \\
\text { ICC }(\mathbf{9 5} \% \mathbf{C I})\end{array}$ \\
\hline TA & $0.92(0.79-0.97)$ & $0.87(0.76-0.95)$ \\
SA & $0.86(0.65-0.95)$ & $0.96(0.90-0.98)$ \\
LCEA & $0.92(0.81-0.97)$ & $0.89(0.71-0.96)$
\end{tabular}

ICC Intraclass correlation coefficient, CI Confidence interval, TA Tönnis angle, LCEA Lateral center edge angle, SA Angle of Sharp.

ICC calculated using the 2-way-random effects model.

Table 3 The changes of spinopelvic parameters after ASD correction

\begin{tabular}{|c|c|c|c|c|c|}
\hline & $\begin{array}{l}\text { Value } \\
\text { mean } \pm S D\end{array}$ & $P$ & & $\begin{array}{l}\text { Value } \\
\text { mean } \pm S D\end{array}$ & $P$ \\
\hline \multicolumn{6}{|c|}{ Sagittal parameters } \\
\hline SVA (cm) & & & $\mathrm{LL}\left({ }^{\circ}\right)$ & & \\
\hline Preop & $13.6 \pm 6.4$ & & Preop & $15.4 \pm 14.5$ & \\
\hline Po $1 Y$ & $3.7 \pm 2.2$ & $<0.001^{*}$ & Po $1 Y$ & $-44.4 \pm 7.7$ & $<0.001^{*}$ \\
\hline SS $\left(^{\circ}\right)$ & & & PT $\left(^{\circ}\right)$ & & \\
\hline Preop & $22.0 \pm 9.0$ & & Preop & $32.9 \pm 8.1$ & \\
\hline Po1Y & $32.4 \pm 8.7$ & $<0.001^{*}$ & Po $1 Y$ & $20.4 \pm 5.7$ & $<0.001^{*}$ \\
\hline TK $\left(^{\circ}\right)$ & & & $\mathrm{PI}\left({ }^{\circ}\right)$ & & \\
\hline Preop & $13.1 \pm 11.7$ & & Preop & $53.9 \pm 9.0$ & \\
\hline Po $1 Y$ & $26.5 \pm 8.7$ & $<0.001^{*}$ & Po 1Y & $54.2 \pm 9.0$ & 0.143 \\
\hline TLK $\left(^{\circ}\right)$ & & & $\mathrm{PI}-\mathrm{LL}\left({ }^{\circ}\right)$ & & \\
\hline Preop & $8.6 \pm 12.1$ & & Preop & $37.1 \pm 16.2$ & \\
\hline PO 1Y & $7.5 \pm 8.2$ & 0.458 & Po $1 Y$ & $9.6 \pm 5.5$ & $<0.001^{*}$ \\
\hline \multicolumn{6}{|c|}{ Coronal parameters } \\
\hline $\mathrm{CB}(\mathrm{mm})$ & & & $\mathrm{PO}\left({ }^{\circ}\right)$ & & \\
\hline Preop & $10.3 \pm 8.6$ & & Preop & $1.0 \pm 0.9$ & \\
\hline Po $1 Y$ & $3.6 \pm 2.8$ & $<0.001^{*}$ & Po $1 Y$ & $0.6 \pm 0.6$ & $0.002^{*}$ \\
\hline
\end{tabular}

Preop Preoperative, Po $1 Y$ 1-year postoperative, SVA Sagittal vertical axis, SS Sacral slope, TKThoracic kyphosis, TLKThoracolumbar kyphosis, LL Lumbar lordosis, PT Pelvic tilt, PI Pelvic incidence, CB Coronal balance, PO Pelvic obliquity, $S D$ Standard deviation.

The data in the table are presented as the mean \pm SD.

$\mathrm{P}$, Comparison between preoperative and postoperative outcomes using paired t test.

* Statistically significant $(p<0.05)$ 
Table 4 Comparison of radiographic acetabular parameters between pre- and postoperative values

\begin{tabular}{|c|c|c|c|c|}
\hline & \multicolumn{2}{|l|}{ Right Side } & \multicolumn{2}{|l|}{ Left Side } \\
\hline & $\begin{array}{l}\text { Value } \\
\text { mean } \pm S D\end{array}$ & $P$ & $\begin{array}{l}\text { Value } \\
\text { mean } \pm S D\end{array}$ & $P$ \\
\hline \multicolumn{5}{|l|}{ TA $\left(^{\circ}\right)$} \\
\hline Preop & $7.5 \pm 2.4$ & & $7.3 \pm 2.7$ & \\
\hline Po $1 Y$ & $5.7 \pm 1.7$ & $<0.001^{*}$ & $5.5 \pm 1.8$ & $<0.001^{*}$ \\
\hline \multicolumn{5}{|l|}{ LCEA $\left(^{\circ}\right)$} \\
\hline Preop & $33.1 \pm 4.7$ & & $35.1 \pm 5.3$ & \\
\hline Po 1Y & $37.3 \pm 4.8$ & $<0.001^{*}$ & $38.5 \pm 4.9$ & $<0.001^{*}$ \\
\hline \multicolumn{5}{|l|}{$S A\left(^{\circ}\right)$} \\
\hline Preop & $37.1 \pm 3.3$ & & $36.5 \pm 3.5$ & \\
\hline Po $1 Y$ & $39.1 \pm 3.4$ & $<0.001^{*}$ & $38.8 \pm 3.8$ & $<0.001^{*}$ \\
\hline
\end{tabular}

Preop Preoperative, Po $1 Y$ 1-year postoperative, TA Tönnis angle, LCEA Lateral center edge angle, SA Angle of Sharp.

The data in the table are presented as the mean \pm SD.

$\mathrm{P}$, Comparison between preoperative and postoperative outcomes using paired t test.

*, statistically significant $(p<0.05)$
The changes of radiographic parameters for acetabular coverage after ASD correction

The surgical correction for ASD resulted in a significant decrease of TA $(p<0.001)$, increase in LCEA $(p<0.001)$ and SA $(p<0.001)$, on both sides, respectively (Table 4$)$ (Fig. 1).

\section{Comparison of the change of acetabular coverage after ASD correction according to PI}

We further evaluated the difference in outcomes by dividing the patients into 3 subgroups according to PI: Group I, PI $\leq 45^{\circ}$, Group II, $45^{\circ}<\mathrm{PI} \leq 60^{\circ}$, and Group III, PI $>60^{\circ}$ (Table 5). Although there was statistically significant decrease of TA, increase of LCEA and SA within each group after ASD correction, there were no significant differences among the subgroups by PI except preoperative TA right side, $(p=0.044)$, the 1 -year postoperative LCEA right side $(p=0.045)$ and LCEA right side $(p=0.002)$.

Table 5 Comparison of the change of acetabular coverage after ASD correction according to PI

\begin{tabular}{|c|c|c|c|c|c|c|c|c|}
\hline & $\begin{array}{l}\text { Group I } \\
\left(\mathrm{PI}<45^{\circ}\right)\end{array}$ & $P$ & $\begin{array}{l}\text { Group II } \\
\left(\mathrm{PI} 45-60^{\circ}\right)\end{array}$ & $P$ & $\begin{array}{l}\text { Group III } \\
\left(\mathrm{PI}>60^{\circ}\right)\end{array}$ & $P$ & $\begin{array}{l}\text { Jonckheere- } \\
\text { Terpstra test }\end{array}$ & $\begin{array}{l}\text { Mann- } \\
\text { Whitney U } \\
\text { test }\end{array}$ \\
\hline \multicolumn{9}{|l|}{$\mathrm{TA}\left({ }^{\circ}\right)$} \\
\hline \multicolumn{9}{|c|}{ Right Side } \\
\hline Preop & $9.0 \pm 3.7$ & & $7.0 \pm 1.8$ & & $7.9 \pm 3.0$ & & 0.339 & 0.321 \\
\hline Po 1Y & $7.4 \pm 2.4$ & $<0.001^{*}$ & $5.5 \pm 1.4$ & $<0.001^{*}$ & $5.4 \pm 1.6$ & $<0.001^{*}$ & $0.044^{*}$ & 0.059 \\
\hline \multicolumn{9}{|l|}{ Left Side } \\
\hline Preop & $9.2 \pm 4.3$ & & $6.6 \pm 1.7$ & & $8.1 \pm 3.4$ & & 0.660 & 0.541 \\
\hline Po 1Y & $7.3 \pm 2.7$ & $<0.001^{*}$ & $5.2 \pm 1.4$ & $<0.001^{*}$ & $5.4 \pm 1.6$ & $<0.001^{*}$ & 0.108 & 0.093 \\
\hline \multicolumn{9}{|l|}{$\operatorname{LCEA}\left({ }^{\circ}\right)$} \\
\hline \multicolumn{9}{|l|}{ Right Side } \\
\hline Preop & $31.2 \pm 4.3$ & & $34.1 \pm 4.6$ & & $31.0 \pm 4.8$ & & 0.578 & 0.888 \\
\hline Po 1Y & $33.1 \pm 1.6$ & $<0.001^{*}$ & $38.3 \pm 5.2$ & $<0.001^{*}$ & $37.4 \pm 2.9$ & $<0.001^{*}$ & $0.045^{*}$ & $0.002^{*}$ \\
\hline \multicolumn{9}{|l|}{ Left Side } \\
\hline Preop & $32.0 \pm 4.7$ & & $36.2 \pm 5.4$ & & $33.2 \pm 3.8$ & & 0.863 & 0.541 \\
\hline Po 1Y & $35.0 \pm 2.7$ & $<0.001^{*}$ & $39.4 \pm 5.3$ & $<0.001^{*}$ & $38.1 \pm 3.7$ & $<0.001^{*}$ & 0.174 & 0.139 \\
\hline \multicolumn{9}{|l|}{$\mathrm{SA}\left({ }^{\circ}\right)$} \\
\hline \multicolumn{9}{|l|}{ Right Side } \\
\hline Preop & $37.0 \pm 1.3$ & & $37.1 \pm 3.8$ & & $37.2 \pm 2.5$ & & 0.878 & 0.888 \\
\hline Po 1Y & $38.8 \pm 1.6$ & $<0.001^{*}$ & $38.9 \pm 3.8$ & $<0.001^{*}$ & $40.1 \pm 2.8$ & $<0.001^{*}$ & 0.479 & 0.277 \\
\hline \multicolumn{9}{|l|}{ Left Side } \\
\hline Preop & $36.5 \pm 2.6$ & & $36.5 \pm 3.9$ & & $36.4 \pm 3.3$ & & 0.939 & 1.000 \\
\hline Po 1Y & $40.0 \pm 2.8$ & $<0.001^{*}$ & $38.6 \pm 4.0$ & $<0.001^{*}$ & $39.4 \pm 4.1$ & $<0.001^{*}$ & 0.619 & 0.743 \\
\hline
\end{tabular}

PI Pelvic incidence, Preop Preoperative, Po $1 Y$ 1-year postoperative, TA Tönnis angle, LCEA Lateral center edge angle, SA Angle of Sharp.

The data in the table are presented as the mean \pm SD.

P, Paired-t test between Preop and Po 1Y.

Jonckheere-Terpstra test, among Group I, II and III.

Mann-Whitney U test, between Group I and Group III.

* Statistically significant if $p<0.05$ 


\section{Correlations between spinopelvic parameters and acetabular parameters}

As shown in Table 6, the results from Pearson bivariate correlation analysis between spinopelvic parameters and coronal acetabular coverage parameters revealed that PT (vs TA right: $\mathrm{r}=0.520, p<0.001$; vs TA left: $\mathrm{r}=0.469$, $P<0.001$ ), LL (vs LCEA right: $\mathrm{r}=0.335, P=0.015$ ), and TK (vs TA left: $r=0.289, P=0.038$ ) significantly correlated with coronal acetabular coverage parameters. With stepwise linear regression analysis, it was revealed that $1^{\circ}$ decrease of PT was occurred with $0.117^{\circ}$ decrease of TA right $\left(R^{2}=0.270\right)$, and with $0.111^{\circ}$ decrease of TA left $\left(\mathrm{R}^{2}=0.220\right)$ (Table 7) (Fig. 2).

\section{Discussion}

Our study apparently demonstrated that surgical correction for ASD consequently increased the parameters representing acetabular lateral coverage (decrease of TA, increase of LCEA and SA) on femoral head. However, unlike a similar study on the relationship between acetabular anteversion and spinal deformity correction [3], we could not find a correlation coefficient with statistical significance between the change of PT and other acetabular coverage parameters such as LCEA and SA. In our study, the result from bivariate analysis between spinopelvic parameters and acetabular coverage parameters revealed that change of PT significantly correlated with change of TA. In explanation with linear regression model, although the correlation between TA and PT was low, postoperative TA decreased simultaneously with postoperative decrease of PT compared to their preoperative values.
Table 7 Linear regression analysis of radiographic parameters predicting the changes of TA and PT after ASD correction

\begin{tabular}{lllll}
\hline & $\boldsymbol{B}$ & SE & P-value & $\mathbf{R}^{2}$ \\
\hline $\begin{array}{l}\text { Change of TA Right } \\
\quad \text { Constant }\end{array}$ & -.243 & .413 & & \\
$\quad$ Change of PT & $.117^{* * *}$ & .027 & $<.001$ & .270 \\
$\begin{array}{l}\text { Change of TA Left } \\
\quad\end{array}$ & & & \\
$\quad$ Constant & -.360 & .445 & & \\
$\quad$ Change of PT & $.111^{* * *}$ & .029 & $<.001$ & .220 \\
\hline
\end{tabular}

$B$ Unstandardized Regression Coefficients, SE Standard Error, $R^{2}$ Coefficient of determination

$* * *, P<.001$

TA Tönnis angle, PT Pelvic tilt.

One way to maintain this spinopelvic alignment is to retrovert the pelvis (increase of PT) that may be seen as a backward rotation of the pelvis around the hips [15]. From the perspective of compensatory mechanism for upright posture and horizontal gaze in human, we can infer the acetabular orientation on the basis of the relationship between the spine and the pelvis. When pelvis rotates anteriorly in an increased posterior tilted pelvis, acetabular coverage increased along with decreased PT because the acetabulum is a deep, cup-shaped structure that is normally oriented to face forward and outward, three-dimensionally [8]. Based on these findings, we hypothesized that correction of ASD with increased PT might result in the decrease of PT, and the increase of anterior and lateral acetabular coverage as well. Although TA, LCEA, and SA are anatomical constant parameters of acetabulum, the result of this study demonstrated that

Table 6 Bivariate correlation analysis between the radiographic change of spinopelvic parameters and acetabular coverage parameters after ASD correction

\begin{tabular}{|c|c|c|c|c|c|c|c|}
\hline \multirow[t]{2}{*}{ Change of } & & \multicolumn{2}{|l|}{ TA } & \multicolumn{2}{|l|}{ LCEA } & \multicolumn{2}{|l|}{ SA } \\
\hline & & Right & Left & Right & Left & Right & Left \\
\hline TK & $\begin{array}{l}r \\
p\end{array}$ & $\begin{array}{l}-.254 \\
(.069)\end{array}$ & $\begin{array}{l}-.289^{*} \\
(.038)\end{array}$ & $\begin{array}{l}.155 \\
(.274)\end{array}$ & $\begin{array}{l}.154 \\
(.275)\end{array}$ & $\begin{array}{l}-.154 \\
(.275)\end{array}$ & $\begin{array}{l}-.019 \\
(.894)\end{array}$ \\
\hline TLK & $\begin{array}{l}r \\
p\end{array}$ & $\begin{array}{l}.029 \\
(.836)\end{array}$ & $\begin{array}{l}.034 \\
(.809)\end{array}$ & $\begin{array}{l}.043 \\
(.760)\end{array}$ & $\begin{array}{l}.070 \\
(.621)\end{array}$ & $\begin{array}{l}.207 \\
(.140)\end{array}$ & $\begin{array}{l}.134 \\
(.345)\end{array}$ \\
\hline LL & $\begin{array}{l}r \\
p\end{array}$ & $\begin{array}{l}-.223 \\
(.112)\end{array}$ & $\begin{array}{l}-.171 \\
(.225)\end{array}$ & $\begin{array}{l}.335^{*} \\
(.015)\end{array}$ & $\begin{array}{l}.150 \\
(.289)\end{array}$ & $\begin{array}{l}-.021 \\
(.882)\end{array}$ & $\begin{array}{l}-.123 \\
(.384))\end{array}$ \\
\hline PT & $\begin{array}{l}r \\
p\end{array}$ & $\begin{array}{l}.520^{* * *} \\
(<.001)\end{array}$ & $\begin{array}{l}.469^{* * * *} \\
(<.001)\end{array}$ & $\begin{array}{l}-.202 \\
(.151)\end{array}$ & $\begin{array}{l}-.271 \\
(.052)\end{array}$ & $\begin{array}{l}-.194 \\
(.168)\end{array}$ & $\begin{array}{l}.035 \\
(.804)\end{array}$ \\
\hline SS & $\begin{array}{l}r \\
p\end{array}$ & $\begin{array}{l}-.189 \\
(.178)\end{array}$ & $\begin{array}{l}-.165 \\
(.242)\end{array}$ & $\begin{array}{l}.170 \\
(.228)\end{array}$ & $\begin{array}{l}.155 \\
(.272)\end{array}$ & $\begin{array}{l}.049 \\
(.732)\end{array}$ & $\begin{array}{l}.037 \\
(.793)\end{array}$ \\
\hline PI-LL & $\begin{array}{l}r \\
p\end{array}$ & $\begin{array}{l}.262 \\
(.061)\end{array}$ & $\begin{array}{l}.210 \\
(.135)\end{array}$ & $\begin{array}{l}-.309^{*} \\
(.026)\end{array}$ & $\begin{array}{l}-.080 \\
(.571)\end{array}$ & $\begin{array}{l}.066 \\
(.641)\end{array}$ & $\begin{array}{l}.208 \\
(.138)\end{array}$ \\
\hline
\end{tabular}

TA Tönnis angle, LCEA Lateral center edge angle, SA Angle of Sharp, TK Thoracic kyphosis, TLK Thoracolumbar kyphosis, LL Lumbar lordosis, PT Pelvic tilt, SS Sacral slope, PI Pelvic incidence, $r$ Pearson correlation coefficient

${ }^{*}, p<.05 ;{ }^{* *}, p<.01 ;{ }^{* * *}, p<.001$

$p<0.05$, statistically significant (correlation). 


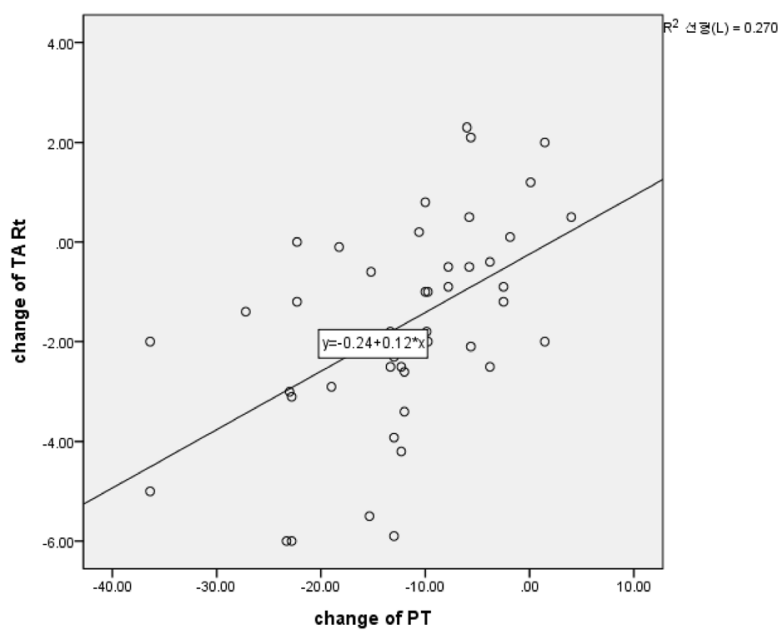

(A) Between change of PT and change of TA Right.

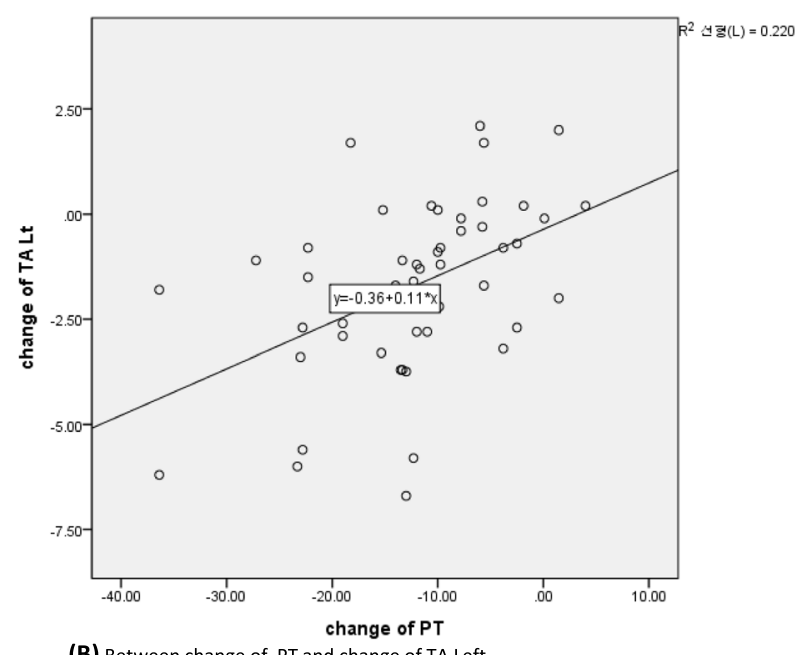

(B) Between change of PT and change of TA Left.

Fig. 2 Graphs of Scatterplot explaining the linear regression between the changes of PT and TA (right and left) after ASD correction. A The relationship between the change of PT and the change of TA right. B The relationship between the change of PT and the change of TA left

surgical correction of ASD was capable of creating statistically significant changes in radiographic measures of TA, LCEA, and SA which were coronal parameters to present acetabular coverage [6]. On the whole, the results of this study reinforced previous studies which reported on the impact of the change of PT on acetabular coronal radiographic measures $[13,16]$.

In another study on the relationship between spinopelvic alignment and acetabular coverage, the measures of LCEA were found to have weak inverse correlation with LL but poor correlation with PI and PT. [17] Moreover, they added TA was not correlated with any of sagittal spinopelvic measurements [17]. According to the recent research by McQuivey et al., higher TA (> 10 degrees) portended a higher risk for revision surgery after arthroscopic surgery on mild hip dysplasia [18]. We also think this change of TA acquired by ASD correction might have an effect on further development of hip pathology. However, on the evidence of the partial discordance between the prior literatures and our study, we couldn't absolutely conclude the universal relationship between the changes of the investigated acetabular parameters and PT. Nonetheless, it is apparent that corrective surgery of patients with ASD can increase LL and decrease PT, and lead to a consistent change of acetabular orientation and lateral coverage.

Above the things aforementioned, the most important clinical implication of the changed acetabular coverage and orientation is thought to focus on the pathogenesis of hip disease, and the correlation with THA [19]. A few studies investigated on the relationship between sagittal pelvic malrotation by PT and THA [20-24]. Tang et al. demonstrated that sagittal pelvic malrotation may potentially lead to the malpositioning of acetabular components despite the careful intraoperative verification of the correct placement [22]. Lazennec et al. reported that patients with spinal fusion demonstrated less adaptability of the lumbosacral junction and longer spinal fusion or inclusion of the pelvis in the fusion critically impacted hip-spine biomechanics and significantly affected the ability to compensate in the standing-to-sitting transition [23]. Buckland et al. reported that since the patients with spinopelvic malalignment had a high prevalence of excessively anteverted acetabular position, sagittal spinal correction following THA resulted in reduced acetabular anteversion, which may have implication for permissible instability [3]. Furuhashi et al. reported spinal long fusion with pelvic fixation could be a risk factor for posterior THA dislocation [24]. However, some authors reported sagittal imbalance did not influence cup anteversion in THA, and therefore the dislocation might not be correlated with spinal sagittal imbalance [25]. If a patient with previous history of THA undergo spinal deformity correction, it is expected that the increased PT as a compensatory mechanism will decrease postoperatively and normalize the anterior and lateral acetabular coverage on femoral head, and which can improve the anterior stability of hip joint. However, in sitting position (flexion of hip joint), it is apprehended that the excessive increase of LL and SS by spinal correction might cause decreased PT that jeopardize posterior dislocation of THA. Meanwhile, when a patient with severe kyphosis and excessively increased PT is planned to undergo THA, the coverage of acetabular component on femoral component is still 
expected to be deficient postoperatively. Theoretically, it is thought that consistent eccentric joint reaction force affects in THA site. Therefore, we believe it is also worth investigating the potential instability, dislocation, polyethylene wear in patients of ASD with increased PT.

The ability of PT is limited by the value of person's own PI. Patients with a small PI have a small capacity to compensate for their sagittal imbalance through pelvis retroversion [26]. Therefore, we initially postulated that the patients with higher PI would have more postoperative decrease in PT and resultant increase in acetabular coverage parameters. However, subgroup analysis according to PI showed that significant differences were found only in the preoperative TA on the both sides and the ultimate postoperative LCEA on the right side. Although there was no significant difference, the patients with high PI $\left(>60^{\circ}\right)$ demonstrated a trend toward the higher TA. This result was thought to imply that the higher PI show the more preoperative tendency to have acetabular orientation to decrease anterior and lateral coverage because they recruited more PT preoperatively as a compensatory mechanism. We think further study with large population is warranted to clarify the relationship between PI and postoperative change of acetabular coverage parameters following ASD correction.

In this study, to focus on the spinal sagittal correction of kyphosis and reduce confounding factors (coronal imbalance or functional scoliosis due to LLD), we excluded the patients who preoperatively showed an LLD of $>10 \mathrm{~mm}$ or a CB of $>3 \mathrm{~cm}$ in whole spine standing AP radiographs. The decision of the exclusion criteria on coronal balance was based on previous literatures [27-30]. Khamis and Carmeli recently reported that an LLD of $>10 \mathrm{~mm}$ could generate substantial changes in gait, with greater differences in leg length having greater impact [27]. Radcliff et al. found an association between pelvic obliquity as a result of LLD and degenerative scoliotic curve morphology in patients undergoing lumbar fusion for the treatment of degenerative scoliosis or degenerative spondylolisthesis [30]. Furthermore, since acetabular orientation was delicately affected by whether weight bearing was applied or not, all the radiographic measures in this study were taken under weight bearing position [30].

There are several limitations in this study. Although correction of ASD improved acetabular coverage parameters with significant changes, we could not directly measure acetabular anteversion, which was considered as a more important parameter for the clinical aspect of hip joint motion. And the clinical outcomes after ASD correction to reveal the clinical relevance to the changes in acetabular coverage parameters were not included. If the comparison between the patients with and without THA was conducted, it would have provided additional clinical implications. Despite the effort to reduce confounding influences on each measurement, PO or LLD were considered to have debilitate the relationship between the change of acetabular coverage parameters and the change of PT achieved by ASD correction due to measurement of acetabular coverage parameters taken not by standing pelvis radiographs but by standing whole spine AP long radiographs.

\section{Conclusions}

This study found that the correlation between the change of PT and coronal acetabular coverage parameter was low although sagittal correction of ASD significantly changed acetabular orientation resulting in increased lateral coverage parameters. However, it is expected that preoperatively increased PT will decrease postoperatively and its resultant increase of anterior and lateral acetabular coverage on femoral head may provide better anterior and lateral stability on hip joint.

\section{Abbreviations \\ ASD: Adult spinal deformity; TA: Tönnis angle; LCEA: Lateral center edge angle; SA: The angle of Sharp; TK: Thoracic kyphosis; TLK: Thoracolumbar kyphosis; LL: Lumbar lordosis; PT: Pelvic tilt; SS: Sacral slope; PI: Pelvic incidence; SVA: Sagittal vertical axis; CB: Coronal balance; LLD: Leg length discrepancy; PO: Pelvic obliquity; AP: Anteroposterior; BMI: Body mass index; THA: Total hip arthroplasty.}

\section{Acknowledgments \\ Not applicable.}

\section{Authors' contributions}

YCK and LC: study concept/design, draft manuscript writing, critical revision; KTK: supervision/critical revision; KYH and YSC: critical revision; JA: manuscript writing, critical revision, statistical analysis; SMK: statistical analysis, acquisition of data; KM: acquisition of data. All authors have read, reviewed, and approved the article.

\section{Funding}

This work was supported by a grant from Kyung Hee University in 2017 (KHU-20170847).

There was no external funding source.

\section{Availability of data and materials}

The patients' data were collected in Kyung Hee University Hospital at Gangdong.

The datasets generated and/or analysed during the current study are available from the corresponding author $(\mathrm{JA})$ on reasonable request.

\section{Declarations}

\section{Ethics approval and consent to participate}

This study was approved by the institutional review board (IRB) of Kyung Hee university hospital at Gangdong (approval number: KHNMC-2020-10-010).

Written informed consent to participate was obtained from all participants.

Consent for publication

We have obtained consent to publish from all participants. 


\section{Competing interests}

The authors declare no personal competing interests in any of the materials, or devices described in this article. No benefits in any form have been received or will be received from a commercial party related directly or indirectly to the subject of this article. (LC: nothing to disclose, YCK: nothing to disclose, KTK: nothing to disclose, $\mathrm{KYH}$ : nothing to disclose, YSC: nothing to disclose, JA: nothing to disclose, SMK: nothing to disclose, KM: nothing to disclose)

\section{Author details \\ ${ }^{1}$ Department of Orthopaedic Surgery, Spine Center, Kyung Hee University Hospital at Gangdong, 892, Dongnam-ro, Gandong-gu, Seoul 05278, South Korea. ${ }^{2}$ Department of Orthopaedic Surgery, Graduate School of Medicine, Kyung Hee University, Kyungheedae-ro, Dongdaemun-gu, Seoul, Republic of Korea.}

Received: 21 June 2021 Accepted: 26 October 2021 Published online: 26 November 2021

\section{References}

1. Birknes JK, White AP, Albert TJ, Shaffrey Cl, Harrop JS. Adult degenerative scoliosis: a review. Neurosurgery. 2008;63(3 Suppl):94-103.

2. Radcliff KE, Kepler CK, Hellman M, Restrepo C, Jung KA, Vaccaro AR, et al. Does spinal alignment influence acetabular orientation: a study of spinopelvic variables and sagittal acetabular version. Orthop Surg. 2014;6(1):15-22

3. Buckland AJ, Vigdorchik J, Schwab FJ, Errico TJ, Lafage R, Ames C, et al. Acetabular Anteversion changes due to spinal deformity correction: bridging the gap between hip and spine surgeons. J Bone Joint Surg Am. 2015:97(23):1913-20.

4. Si G, Li T, Liu X, Liu Z, Li W, Yu M. Correlation analysis between postoperative hip pain and spino-pelvic/hip parameters in adult scoliosis patients after long-segment spinal fusion. Eur Spine J. 2020;29(12):2990-7.

5. Watanabe W, Sato K, Itoi E, Yang K, Watanabe H. Posterior pelvic tilt in patients with decreased lumbar lordosis decreases acetabular femoral head covering. Orthopedics. 2002;25(3):321-4.

6. Henebry A, Gaskill T. The effect of pelvic tilt on radiographic markers of acetabular coverage. Am J Sports Med. 2013:41(11):2599-603.

7. Jamali AA, Mladenov K, Meyer DC, Martinez A, Beck M, Ganz R, et al. Anteroposterior pelvic radiographs to assess acetabular retroversion: high validity of the "cross-over-sign". J Orthop Res. 2007;25(6):758-65.

8. Siebenrock KA, Kalbermatten DF, Ganz R. Effect of pelvic tilt on acetabular retroversion: a study of pelves from cadavers. Clin Orthop Relat Res. 2003;407:241-8

9. Sharp IK. Acetabular dysplasia. J Bone Joint Surg Brit. 1961;43-B(2):268-72.

10. Tönnis D. Congenital dysplasia and dislocation of the hip in children and adults. Berlin: Springer-Verlag; 1987.

11. Janssen MM, Drevelle $X$, Humbert L, Skalli W, Castelein RM. Differences in male and female spino-pelvic alignment in asymptomatic young adults: a three-dimensional analysis using upright low-dose digital biplanar X-rays. Spine (Phila Pa 1976). 2009;34(23):E826-32.

12. Vialle R, Levassor N, Rillardon L, Templier A, Skalli W, Guigui P. Radiographic analysis of the sagittal alignment and balance of the spine in asymptomatic subjects. J Bone Joint Surg Am. 2005:87(2):260-7.

13. Fukushima K, Miyagi M, Inoue G, Shirasawa E, Uchiyama K, Takahira N, et al. Relationship between spinal sagittal alignment and acetabular coverage: a patient-matched control study. Arch Orthop Trauma Surg. 2018;138(11):1495-9.

14. Horton WC, Brown CW, Bridwell KH, Glassman SD, Suk SI, Cha CW. Is there an optimal patient stance for obtaining a lateral 36" radiograph? A critical comparison of three techniques. Spine (Phila Pa 1976). 2005;30(4):427-33.

15. Schwab F, Lafage V, Patel A, Farcy JP. Sagittal plane considerations and the pelvis in the adult patient. Spine (Phila Pa 1976). 2009:34(17):1828-33.

16. Miyasaka D, Sakai Y, Ibuchi S, Suzuki H, Imai N, Endo N. Sex- and agespecific differences in femoral head coverage and acetabular morphology among healthy subjects-derivation of normal ranges and thresholds for abnormality. Skelet Radiol. 2017:46(4):523-31.

17. Pytiak A, Bomar JD, Peterson JB, Schmitz MR, Pennock AT, Wenger DR, et al. Analysis of spinal alignment and pelvic parameters on upright radiographs: implications for acetabular development. J Hip Preserv Surg. 2016;3(3):208-14.

18. McQuivey KS, Secretov E, Domb BG, Levy BA, Krych AJ, Neville M, et al. A multicenter study of radiographic measures predicting failure of arthroscopy in borderline hip dysplasia: beware of the Tonnis angle. Am J Sports Med. 2020;48(7):1608-15

19. Kim WY, Hutchinson CE, Andrew JG, Allen PD. The relationship between acetabular retroversion and osteoarthritis of the hip. J Bone Joint Surg (Br). 2006:88(6):727-9.

20. Kennedy JG, Rogers WB, Soffe KE, Sullivan RJ, Griffen DG, Sheehan LJ. Effect of acetabular component orientation on recurrent dislocation, pelvic osteolysis, polyethylene wear, and component migration. J Arthroplast. 1998;13(5):530-4.

21. Moskal JT, Capps SG. Improving the accuracy of acetabular component orientation: avoiding malposition. J Am Acad Orthop Surg. 2010;18(5):286-96.

22. Tang WM, Chiu KY. Primary total hip arthroplasty in patients with ankylosing spondylitis. J Arthroplast. 2000;15(1):52-8.

23. Lazennec JY, Clark IC, Folinais D, Tahar IN, Pour AE. What is the impact of a spinal fusion on Acetabular implant orientation in functional standing and sitting positions? J Arthroplast. 2017;32(10):3184-90.

24. Furuhashi $\mathrm{H}$, Togawa D, Koyama $\mathrm{H}$, Hoshino $H$, Yasuda $T$, Matsuyama Y. Repeated posterior dislocation of total hip arthroplasty after spinal corrective long fusion with pelvic fixation. Eur Spine J. 2017;26(Suppl 1):100-6.

25. Haws BE, Khechen B, Patel DV, Louie PK, lyer S, Cardinal KL, et al. Sagittal imbalance does not influence cup Anteversion in Total hip Arthroplasty dislocations. Clin Spine Surg. 2019;32(1):E31-6.

26. Roussouly P, Pinheiro-Franco JL. Biomechanical analysis of the spino-pelvic organization and adaptation in pathology. Eur Spine J. 2011;20(Suppl 5):609-18.

27. Khamis S, Carmeli E. The effect of simulated leg length discrepancy on lower limb biomechanics during gait. Gait Posture. 2018:61:73-80.

28. Defrin R, Ben Benyamin S, Aldubi RD, Pick CG. Conservative correction of leg-length discrepancies of $10 \mathrm{~mm}$ or less for the relief of chronic low back pain. Arch Phys Med Rehabil. 2005;86(11):2075-80.

29. Sheha ED, Steinhaus ME, Kim HJ, Cunningham ME, Fragomen AT, Rozbruch SR. Leg-length discrepancy, functional scoliosis, and low back pain. JBJS Rev. 2018;6(8):e6

30. Radcliff KE, Orozco F, Molby N, Chen E, Sidhu GS, Vaccaro AR, et al. Is pelvic obliquity related to degenerative scoliosis? Orthop Surg. 2013;5(3):171-6.

\section{Publisher's Note}

Springer Nature remains neutral with regard to jurisdictional claims in published maps and institutional affiliations.

Ready to submit your research? Choose BMC and benefit from

- fast, convenient online submission

- thorough peer review by experienced researchers in your field

- rapid publication on acceptance

- support for research data, including large and complex data types

- gold Open Access which fosters wider collaboration and increased citations

- maximum visibility for your research: over 100M website views per year

At BMC, research is always in progress.

Learn more biomedcentral.com/submissions 